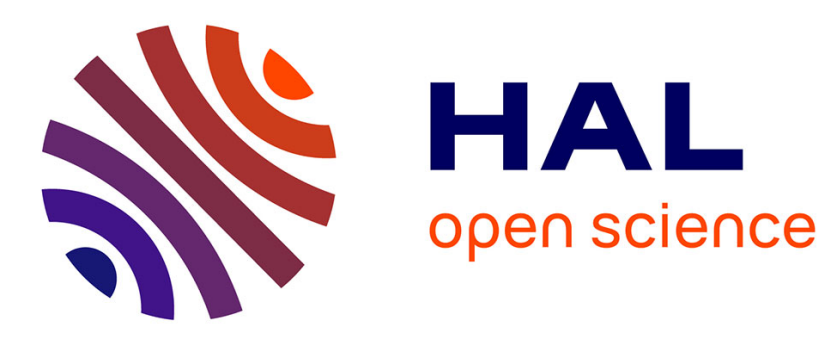

\title{
Thermal diffusivity measurement by photothermal radiometry under PRBS excitation
}

\author{
K. Hakem, M. Heuret, M. Egee
}

\section{To cite this version:}

K. Hakem, M. Heuret, M. Egee. Thermal diffusivity measurement by photothermal radiometry under PRBS excitation. Journal de Physique IV Proceedings, 1994, 04 (C7), pp.C7-51-C7-54. 10.1051/jp4:1994713 . jpa-00253184

\section{HAL Id: jpa-00253184 https://hal.science/jpa-00253184}

Submitted on 1 Jan 1994

HAL is a multi-disciplinary open access archive for the deposit and dissemination of scientific research documents, whether they are published or not. The documents may come from teaching and research institutions in France or abroad, or from public or private research centers.
L'archive ouverte pluridisciplinaire HAL, est destinée au dépôt et à la diffusion de documents scientifiques de niveau recherche, publiés ou non, émanant des établissements d'enseignement et de recherche français ou étrangers, des laboratoires publics ou privés. 


\title{
Thermal diffusivity measurement by photothermal radiometry under PRBS excitation
}

K. Hakem, M. Heuret and M. Egee

GRSM/LEO, Faculté des Sciences, BP. 347, 51062 Reims cedex, France

\begin{abstract}
Photothermal radiometry is a thermal method leading to the measurement of thermal diffusivity. In this paper we use a pseudo-random excitation. The measurement is accomplished by comparing the experimental results in phase, with some curves, calculated by a mathematical modelling (bidimensionnal and axisymetrical).
\end{abstract}

\section{INTRODUCTION}

Among the various methods which allow for thermal diffusivity measurements, those that use thermal generated woves are becoming more developed and are currently reaching the industrial sector (Flash Method [1,2], Mirage Effect [3]...). Photothermal radiometry is achieved without contact and is non destructive. There are usually two types of temporal excitation distributions that are used: pulsed or sinusoidal [4]. In the first case, the thermal relaxation of the sample surface is observed. In the second case, it is the amplitude and the phase that are measured. Henceforth, we propose to use an excitation of random type [5,6,7] (PRBS: Pseudo Random Binary Sequence). The afore mentioned method has a double interest in comparison with the other methods currently in use. There is less thermal stress on the sample than with pulsed excitation, and the multi-frequency analysis is faster than with sinusoidal excitation.

The diffusivity is deduced from the phase versus frequency curves. The analysis is supported by both the development of theoretical modelling, and a sensitivity study of the phase curves to the thermal diffusivity. The measurement is done by placing the experimental curve in a network of theoretical ones. The quality of this operation depends on two factors :

- the first one is due to the equipment itself (time shift for example)

- the second one is due to the lack of precision in the knowledge of samples that are considered as standards (thickness and volume absorption for example)

\section{THEORY}

Our intention was to determine the harmonic multifrequency response of a sample. The laboratory had previously developed an axisymetrical bidimensional model [8], and it was thus reused. It takes into account parameters such as :

- the geometry of the laser beam;

- the bidimensional thermal diffusion inside the sample;

- the thicknesses of various layers;

- etc..

This modelling considers a perfect conservation of both the heat flux and the temperature at the interfaces. It allows for the calculation of the photothermal signal at the end of the detection chain : 
$\varphi(f, a, \ldots)=\tan ^{-1}\left(\frac{\frac{r_{d}^{2}\left(A_{0}^{j}+B_{0}^{j}-E_{0}^{j}(a, \ldots)\right)}{2}+\sum_{n=1}^{\infty} \frac{r_{d}}{\delta_{n}} J_{1}\left(\delta_{n} r_{d}\right)\left[A_{n}^{j}+B_{n}^{j}-E_{n}^{j}(a, \ldots)\right]}{\frac{r_{d}^{2}\left(A_{0}^{r}+B_{0}^{r}-E_{0}^{r}(a, \ldots)\right)}{2}+\sum_{n=1}^{\infty} \frac{\mathbf{r}_{d}}{\delta_{n}} J_{1}\left(\delta_{n} r_{d}\right)\left[A_{n}^{r}+B_{n}^{r}-E_{n}^{r}(a, \ldots)\right]}\right)$

where :
$A_{i}, B_{i}, \delta_{n}$
Complex integration constants
$E_{i}(a, \ldots)$
Input complex vector (depend on thermal diffusivity, thickness, ...)
$J_{l}$
First order Bessel's function
$r_{d}$
Detector radius
$a, a_{0}$
Thermal diffusivity
$\varphi$
Photothermal signal phase

In order to facilitate the use of this rather complex function, we have linearized the phase according to a first order Taylor series. This leads to a simplified expression of the phase versus the thermal diffusivity. To achieve that point, we must assume that all the other physical parameters (thickness, absorption,..) remain constant and independant of the thermal diffusivity. The development of the phase in the neighbourhood of a value $a_{0}$ thus gives :

$\varphi(\mathrm{f}, \mathrm{a})=\varphi\left(\mathrm{f}, \mathrm{a}_{\circ}\right)+\left(\mathrm{a}-\mathrm{a}_{\circ}\right) \frac{\partial \varphi(\mathrm{f}, \mathrm{a}}{\partial \mathrm{a}}$

One can define a coefficient of sensitivity [9] :

$\mathrm{C}_{\mathrm{a}_{0}}(\mathrm{f})=\mathrm{a}_{0} \frac{\partial \varphi\left(\mathrm{f}, \mathrm{a}_{0}\right)}{\partial \mathrm{a}}$

The distribution of coefficient $\mathrm{C}$ versus the frequency (figure 1) permits an adequate choice of the frequency range $\Delta f$, for the measurement. Such a procedure can be applied for any other parameter of the theoretical modelling.

\section{EXPERIMENTAL RESULTS}

The experimental set-up is described in figure 2 . Its main components are :

- a $500 \mathrm{~mW}$ pig-tailed laser diode,

- two off-axis parabolic mirrors,

- a plane mirror, drilled in its middle in order to let the excitation beam go through (equivalent to a semi reflector blade),

- an MCT detector, $100 \mu \mathrm{m} \times 100 \mu \mathrm{m}$.

The infrared detector and the sample are placed at the optical foci of the system. A PC computer pilots the equipment, via two electronic cards (preamplifier and amplifier). The operator has the choice between a sinusoidal or a PRBS excitation. In the first case, the detection is handled by a lock-in card, whereas in the second case the system provides the impulsive response, which is later transformed in phase and amplitude by a FFT. Precautions were taken in order to attenuate major errors in the diffusivity measurement. The preamplifier and the detector bandwidthes are much larger than those of the analyzed signal itself. Typically, the equivalent excitation frequency range is $[0,05 . .500 \mathrm{~Hz}]$ whereas the amplifier bandwidth is [DC .. $1 \mathrm{Mhz}$; the MCT being of broadband type, with a high cut-off of several Mhz. A DC connection was chosen in order to avoid any primary capacity induced phase shifts. This DC level, and its fluctuations, must be remove from the complete signal. A specific procedure is used, which at first occurs inside the preamplifier itself, with a dedicated electronic compensation circuit. In a second stage, a software corrects the signal from what may not have been completely filtered before. 
First of all, the PRBS technique was validated by comparing its results with those given by a traditional and well-known method : lock-in detection. This study resulted in the distribution of the phase versus the frequency, and the histogram of its standard deviation. Figure 3 shows two phase curves abtained on a glass blade of well known thermophysical parameters : one with a lock-in detection, and the other with the PRBS technique. The similarity of these results is obvious.

In order to build the histogram of the phase variations, several sample series were tested. They consist of various glass blades of the same diffusivity, but of different thicknesses and absorption coefficient. The Yaxis on the histogram shows the number of times (expressed in \%) where the same variation is obtained, whatever the frequency and the sample. The successive classes of deviation are reported with their mean value on the $\mathrm{X}$-axis. Figures 4 and 5 show the histograms respectively obtained with sinusoidal and PRBS excitation. On these two charts, one observes that $95 \%$ of the deviations are less than to $0.5^{\circ}$ in the case of the lock-in detection, and less than to $0.6^{\circ}$ in the case of PRBS. Furthermore, one notes that the distribution is centered on $0.15^{\circ}$ in the case of the lock-in detection, and centered on $0.5^{\circ}$ in the case of PRBS. Consequently, if one considers a frequency individually taken, the PRBS technique is less precise than a traditional lock-in method. This disadvantage is largely diminished if a complete range of frequencies is taken into account. In order to evaluate the final precision of the method, measurements were performed on a series of glass blades of unique absorption coefficient $\left(598 \mathrm{~m}^{-1}\right)$, but with various thicknesses. By the adjustement of the experimental phase curves in the theoretical network, a thermal diffusivity of $0.2110^{-6} \mathrm{~m}^{2} \mathrm{~s}^{-1}+/-3.5 \%$ was deduced. Figure 6 depicts the result for the $2 \mathrm{~mm}$-thick blade.

\section{CONCLUSION}

The method that is proposed allows for in-situ diffusivity measurements of various samples : monolayers or bilayers, semitransparent or opaque. The spatial resolution is on the order of $500 \mu \mathrm{m}$. Dielectric materials can be tested without difficulty, whereas the limited power of the laser source makes the analysis of metals more problematic. The first layer can vary within the range a few $\mu \mathrm{m}$ - a few mm, and no special preparation of the sample is required. The method gives both the impulsive and the harmonic responses, thus allowing for a wider range of comparison with theoretical modellings.

Our further field of study is oriented towards the simultaneous measurement of thickness and thermal diffusivity, in the case of semitransparent materials.

\section{References}

[1] Parker W.J., Jenkins R.J., Butler C.P. and Abbott G.L.,. Journal of Applied Physics, 32, N$^{\circ} 9$ (1961).

[2] Degiovanni A. et Laurent M.,. Rev. Phys. Appl. 21, 229-237.

[3] Aamodt L.C. and Murphy J.C., Journal of Applied Physics, 52, № 8 (1981).

[4] Dartois R., Egée M., Marx J. et Van Schel E., Rev. Gén. Therm. Fr., 301 (1987) p. 22-32.

[5] Sugitani Y., Uejima A.and Kato K., Journal of Photoacoustics, 1-2, (1982) p $217-236$.

[6] Mandelis A., 7th International Topical Meeting on Photoacoustic and Photothermal Phenomena. Holand 1991.

[7] Mérienne E., Hakem K. et Egée M., Rev. Gén. Therm. Fr., 360 (1991).

[8] Potier F. - Radiométrie photothermique appliquée à la caractérisation et au contrôle du traitement thermique des métaux. Ph. D. Thesis Reims France (1989).

[9] Beck J.V. and Arnold K.J., Parameter estimation in engineering and science. (WILEY J., Interscience publication, 1977). 


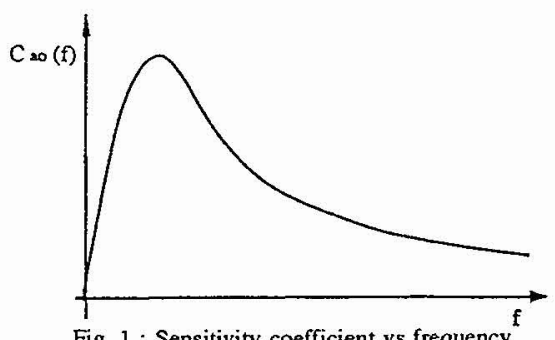

Fig. 1: Sensitivity coefficient vs frequency

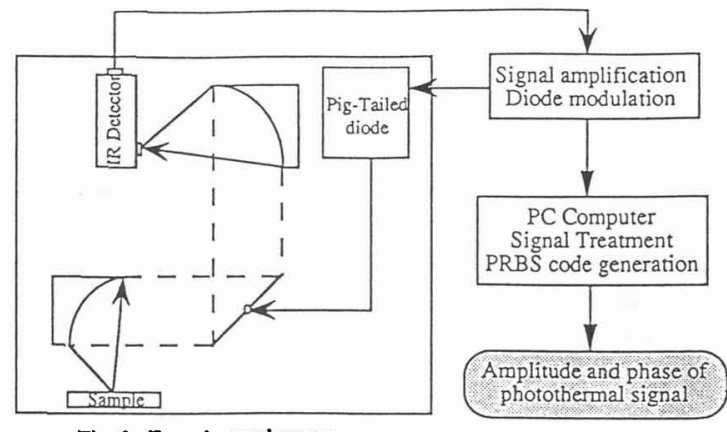

Fig. 2: Experimental set-up

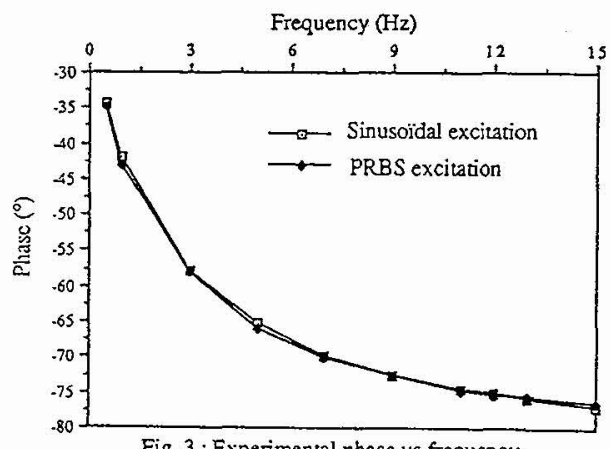

Fig. 3 : Experimental phase vs frequency

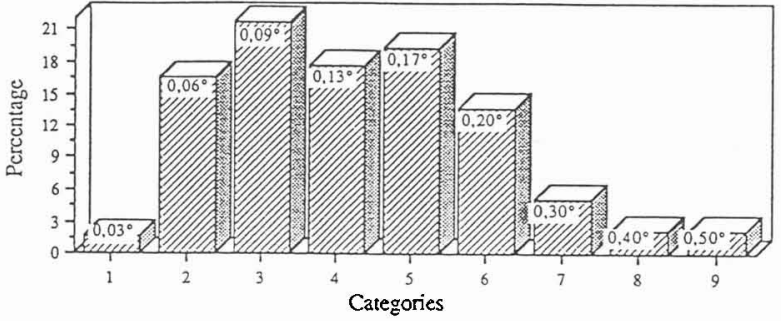

Fig. 4 : Standard deviation histogram under sinusoïdal excitation

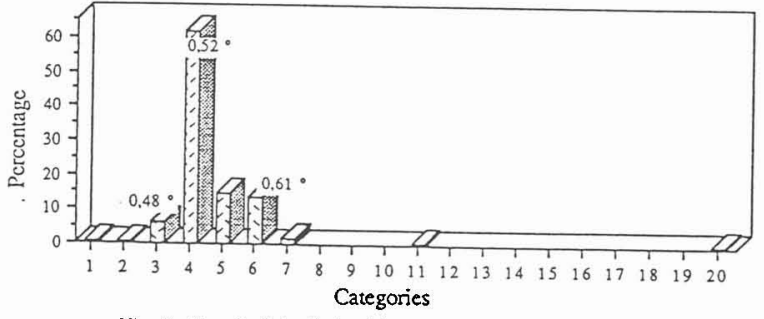

Fig. 5 : Standard deviation histogram under PRBS excitation

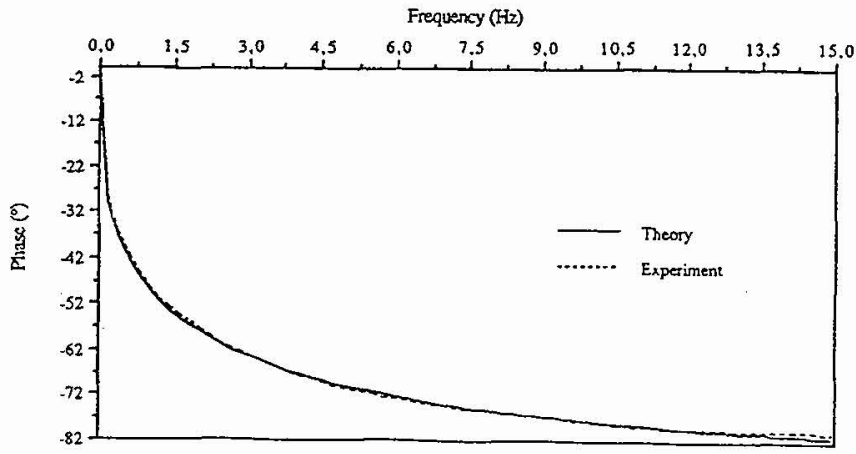

Fig. 6 : Adjustment of the experimental curve 